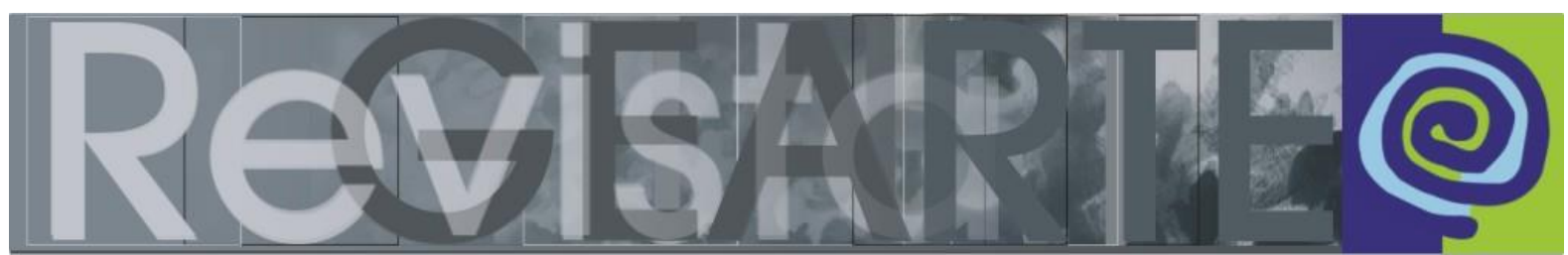

e-ISSN 2357-9854

\title{
Experimentação audiovisual: considerações sobre a produção de subjetividades na grande mídia
}

\author{
Jéssica Thaís Demarchi (Universidade Federal de Pelotas - UFPel, \\ Pelotas/RS, Brasil)
}
Cláudio Tarouco de Azevedo (Universidade Federal de Pelotas - UFPel, Pelotas/RS, Brasil)

\begin{abstract}
RESUMO - Experimentação audiovisual: considerações sobre a produção de subjetividades na grande mídia - $\mathrm{O}$ artigo que aqui se apresenta vislumbra uma discussão acerca de alguns aspectos da produção de subjetividades nutrida por determinados recortes da grande mídia audiovisual. Tendo sido o método cartográfico o fio condutor dos procedimentos de construção da presente pesquisa, será apresentado um programa de oficinas de vídeo experimental que foi desenvolvido como projeto pedagógico. Baseadas na lógica ecosófica, as oficinas ambicionam a problematização dos mecanismos de produção de subjetividades na esfera audiovisual que permeia a cultura visual contemporânea. Além disso, o projeto deseja auxiliar os participantes para que, através de uma desestabilização do olhar acostumado aos padrões midiáticos, possam explorar suas subjetividades de maneira livre por intermédio das conexões de sentidos engendradas durante a experiência.
\end{abstract}

\section{PALAVRAS-CHAVE}

Vídeo experimental. Ecosofia. Mídia.

ABSTRACT - Audiovisual experimentation: considering the subjectivity production in the mainstream media - The present article envisions a discussion on aspects of the production of subjectivities nourished by certain fragments of the mainstream audiovisual media. With the cartographical method being used as the conducting wire of the construction of this research, a program of workshops of experimental video will be presented. It was developed as a pedagogical project. The workshops, based on the ecosophical logic, aspire a problematization of the mechanisms of production of subjectivities in the audiovisual field that permeates the contemporary visual culture. Through a destabilization of the view accustomed to media standards, the project aims to help the participants to explore their subjectivities in a free way through the connections of meanings engendered during the experience.

KEYWORDS

Experimental video. Ecosophy. Media.

\section{O fluxo imagético na pós-modernidade}

Frequentemente a pós-modernidade é descrita como ponto de crise da modernidade. Genericamente e dito em breves palavras, isso se deve centralmente ao fato de que o legado da filosofia ocidental, cujo mote consiste na busca constante do entendimento de mundo através de cânone unificador e capaz de estabelecer verdades generalizantes, é contraposto pelo relativismo. 
Percebe-se a fragmentação das experiências humanas e a fragilidade das estruturas unificantes, de modo que não só a esfera dos sentidos opera com a multiplicidade, mas também o campo da razão está conectado a ela. A realidade tal qual a conhecemos é compreendida em sua condição de mutabilidade e não se baseia em verdades absolutas, visto que sua base é constituída por construções sociais e montagens de linguagem.

A representação imagética da realidade também figura um cenário de crise já que os índices de visualidade que passam a orientar a compreensão de mundo não têm a obrigação de seguir modelos fixos como acontecia com o figurativismo na pintura até a década de 1870. A pluralidade do discurso visual rompe com as fronteiras e restrições da representação do real. Nesse sentido, Nicholas Mirzoeff (2003, p. 27) constata que na contemporaneidade "a imagem filmada ou a fotografia já não incluem a realidade em seu índice porque todos sabemos que ela pode ser manipulada por computação de maneira imperceptível”.

Ele explica que a imagem passa a estar revestida por um caráter de virtualidade quando a potência da transmissão da imagem em tempo real se sobrepõe ao próprio fato representado, fazendo com que o tempo real tenha mais destaque do que o espaço real. A ideia de realidade passa por uma ordem de desestabilização em função do poder que a virtualidade adquire sobre o fato em si.

O autor diz que ao mesmo tempo em que essa virtualização parece ludibriar o nosso entendimento, criando assim uma crise visual, presenciamos também uma época na qual a sofisticação das visualidades avança de maneira extraordinária. $\mathrm{O}$ fluxo em escala global dessas imagens constitui ele mesmo uma espécie de "produto", ocupando um patamar cada vez mais importante nas redes e na interação social de modo mais amplo.

A exorbitância de imagens conduz à cultura visual, que por sua vez caracteriza uma sobrecarga visual e crise da informação no cotidiano. Com a intenção de trabalhar no contexto dessa realidade virtual, Mirzoeff esclarece:

A distância entre a riqueza da experiência visual na cultura pós-moderna e a habilidade para analisar esta observação cria a oportunidade e a necessidade 
de converter a cultura visual em campo de estudo. [...] A cultura visual se interessa pelos acontecimentos visuais em que o consumidor busca a informação, o significado ou o prazer conectados com a tecnologia visual (MIRZOEFF, 2003, p. 19).

Vislumbrando algumas das colocações do autor acerca da cultura visual como investigação da globalização pós-moderna das visualidades na experiência cotidiana, buscamos desenvolver um projeto pedagógico com oficinas de vídeo experimental. $\mathrm{Na}$ elaboração deste programa de oficinas, ao entrelaçar o ensino de Artes Visuais e uma parcela dos fenômenos que integram a cultura visual, tencionamos problematizar alguns mecanismos de produção de subjetividades na grande mídia audiovisual. Destacamos que na presente discussão a referência ao termo grande mídia se dá no sentido dos canais de maior ibope da televisão aberta brasileira, o que não significa que outros veículos de comunicação que compartilham das mesmas características não possam estar vinculados ao trabalho.

\section{Produção de subjetividades na indústria cultural}

A quantidade de pessoas que veem e se relacionam com o mundo ao seu redor através de aparatos de produção e exibição visual aumenta consideravelmente dia após dia. Por conseguinte, "o trabalho e o tempo livre estão centrando-se progressivamente nos meios visuais de comunicação" (MIRZOEFF, 2003, p. 17).

O abundante circuito de visualidades assegura a constante manutenção das principais engrenagens da indústria cultural, que faz circular, divulga e produz os bens de consumo. Segundo Theodor Adorno (2016), tal indústria não consiste unicamente nas imagens e conteúdos midiáticos que caçam a contemplação do espectador, mais do que isso, ela é uma relação entre os indivíduos mediada pela enxurrada imagética que funciona com força total quando o sistema econômico já solidificou seu poderio dominante sobre a sociedade.

O mote basilar de uma sociedade orientada nessa direção é a dinâmica consumista. Assim, a seleta elite que comanda as maiores e mais influentes empresas capitalistas ocupa um lugar privilegiado de autoridade sobre o curso da vida da população em geral. Os valores cultivados por essas grandes entidades, cujo objetivo 
central é o lucro, são injetados nos meios de massa, tendo assim o direito de participar do manejo dos canais de comunicação com maior volume de consumidores.

Marilena Chaui (2006) constata que as corporações multimilionárias firmam parcerias cada vez mais sólidas com inúmeros serviços de comunicação como jornais, revistas, canais de televisão e redes de telefonia, ocupando assim, posições de controle sobre o que pode ou não ser explicitado e como a (des)informação deve ser oferecida à população.

A lógica midiática no contexto da indústria cultural tende a produzir uma matriz de comportamentos a serem absorvidos pela população. Ela faz isso criando protótipos ideais para todas as esferas da vida: forma física, laser, sucesso, relacionamentos, vida profissional, religião, cultura, educação, entre outros. A participação de milhões em tal indústria impõe métodos de reprodução que, por seu turno, fazem com que necessidades e desejos iguais sejam satisfeitos com produtos estandardizados. Adorno (2016, p. 9) afirma que os "clichês seriam causados pelas necessidades dos consumidores: por isso seriam aceitos sem oposição".

Existe uma tentativa de equalização dos indivíduos no momento em que, ao estarem sujeitos a conteúdos muito parecidos, são pouco valorizadas as particularidades de cada um e pretende-se uma espécie de uniformização do todo. $O$ modo de vida que o poder econômico busca impor às pessoas não se identifica, em essência, com aquilo que os indivíduos são ou poderiam vir a ser.

Ao passo em que a contemplação sem efetiva ação interativa se normatiza no cotidiano do sujeito, menos ele vive e conhece a verdade. Quanto maior é a força do entrelaçamento entre o indivíduo e o imagético dominante como se este representasse o seu reflexo, maior é o enfraquecimento da compreensão de sua natureza genuína. Os movimentos que o sujeito realiza são menos seus do que gerenciados pelos fundamentos da indústria cultural.

\section{Algumas contribuições ecosóficas}

Para que possamos problematizar a forma como a produção de subjetividade se dá no meio midiático, é importante que citemos o conceito de subjetividade. Nicolas 
Bourriaud (2009, p. 127) diz que a subjetividade em Félix Guattari consiste em um "conjunto de relações que se criam entre o indivíduo e os vetores de subjetivação que ele encontra, individuais ou coletivos, humanos ou inumanos". A estruturação da subjetividade coletiva, que se dá por intermédio dos fios tecidos pelo meio e pelo consumo cultural, bem como pela maquinaria informacional, exala os significantes que, por sua vez, produzem territórios mínimos com os quais o indivíduo será capaz de fundar sua própria subjetividade ao identificar-se. Nesse jogo em que o sujeito constitui seus códigos subjetivos, novas relações vão sendo encetadas em conexões peculiares com a mente e o corpo. Destarte, manifestam-se novos dispositivos de contraposição às rígidas normatizações ideológicas e comportamentais.

Roberta Romagnoli (2009) complementa ao explicar que o organismo da subjetividade é instituído por planos de força e linhas multiformes que atuam simultaneamente. Nesse campo, existem as linhas duras encarregadas das divisões binárias, como a classificação dos sujeitos de acordo com camada social, sexo e área profissional, por exemplo. Além destas, encontram-se as linhas flexíveis que viabilizam o afetamento da subjetividade, produzindo as zonas de indeterminação que permitem ao indivíduo a criação de conexões e agenciamentos. Quando esses processamentos são efetuados, se desencadeiam algumas linhas de fuga que convergem em criações que desvelam o novo. Essas formações são orientadas sempre de maneira coletiva, relacionando-se com elementos situados para além do sujeito.

A fim de seguirmos a discussão a respeito da subjetividade na grande mídia, estabelecemos algumas aproximações com a lógica ecosófica em Guattari (2001). As ponderações do autor são capazes de apontar para alguns mecanismos dos meios de comunicação que afetam nossa maneira de entender o meio em que vivemos, de conectar-se com ele e de reconhecer e produzir sentidos em seu contexto. Guattari sintetiza esse processo ao dizer que a nossa experiência de vida vem sendo gangrenada pela mídia.

Explorando relações de poder existentes nas estruturas de bens, de serviços e de produção de signos que vem se instaurando na sociedade, o autor explica que a relação da subjetividade (seja ela vegetal, social, cósmica ou animal) com sua 
exterioridade vem sofrendo um processo de involução, de forma que o singular vai dissipando suas peculiaridades. O autor diz que só uma articulação ético-política entre os três registros ecológicos (meio ambiente, relações sociais e subjetividade humana), que ele chama de ecosofia, seria capaz de operar mudanças efetivas, representando um vigor de confronto às consequências do capitalismo pós-industrial, o qual ele denomina Capitalismo Mundial Integrado (CMI). Os princípios cultivados pelo CMI tendem a espargir sua pujança não só pelos mecanismos de produção de bens e serviços, mas também através dos veículos de comunicação de massa. A parceria estabelecida entre o sistema regido pelo capital e a mídia auxilia na conservação dos valores preconceituosos e excludentes entre imigrados, mulheres e toda uma parcela populacional que tem sido incansavelmente inferiorizada e explorada.

O caminho traçado pela hipervalorização da fabricação e acelerada circulação de bens imateriais e materiais é direcionado para zonas imensas de blocos homogêneos de criação de sentidos, com recursos de significação padronizados e aos poucos esvaziados. A mídia toma as rédeas do maior volume de zonas existenciais com a finalidade de dominá-las. Assim, a subjetividade controlada pelo capitalismo é mediocrizada por conta própria em um sentido contínuo de reprodução.

O sistema econômico em voga tem como um de seus principais alvos a laminagem das subjetividades como matéria prima para seu conglomerado "produtivoeconômico-subjetivo" (GUATTARI, 2001, p. 32). Na tentativa de contribuir com a produção de artefatos de confronto ao acúmulo dos processos de subjetivação engolfados em arcaísmos, Guattari fala sobre a necessidade de uma reorganização dos propósitos e práticas que engendram o movimento social nas condições atuais e complementa protelando o seguinte:

E façamos votos para que no contexto das novas distribuições das cartas da relação entre o capital e a atividade humana, as tomadas de consciência ecológicas, feministas, anti-racistas etc, estejam mais prontas a ter em mira, a título de objetivo maior, os modos de produção da subjetividade - isto é, de conhecimento, cultura, sensibilidade e sociabilidade - que dizem respeito a sistemas de valor incorporai, os quais a partir daí estarão situados na raiz dos novos Agenciamentos produtivos. [...] Longe de buscar um consenso cretinizante e infantilizante, a questão será, no futuro, a de cultivar o dissenso e a produção singular de existência (GUATTARI, 2001, p. 33). 
O autor aponta a ecosofia como recurso em prol da constituição de zonas de consciência pluralizadas capazes de engendrar relações de empatia, sensibilidade, respeito ao meio ambiente e à multiplicidade dos sujeitos, companheirismo e igualdade. Uma perspectiva aclarada por este lume coordenaria empreendimentos insólitos no âmbito do microssocial, da micropolítica e da solidariedade, unindo-os a novas ações ético-estéticas e de exploração do desenvolvimento do inconsciente.

Isto posto, o diferente e o excêntrico seriam capazes de atuar em consonância com um modo de governar mais humanitário e livre de engessamentos. Far-se-ia necessária uma reoxigenação no sangue que corre pelas veias do organismo social a fim de tentar amenizar as intoxicações causadas pelas investidas capitalistas. Esse procedimento demandaria não só regenerações nos tecidos políticos no sentido burocrático e legislativo, mas principalmente nas camadas de produção subjetiva, auxiliando na criação de movimentos e experiências que visem a nutrição de mentalidades autônomas que cultivem as peculiaridades e as singularidades.

No contexto da mídia guiada pela razão do consumo, a constituição das identidades e alteridades tende a ser arquitetada por intermédio de configurações de identificação e imitação e é "no sentido dessa psicologia de massas maleáveis que trabalha a grande mídia" (GUATTARI, 2001, p. 45). Por outro lado, na ótica ecosófica, o eu e o outro são fundados na forma como os indivíduos conseguem deslocar-se dos territórios existenciais, procurar por diferentes áreas para se desenvolver, realocar-se e transcenderem-se a si mesmos acionando dispositivos de correlação com o referente.

Não se trata de uma abolição ou condenação do aparato midiático, mas sim de uma renovação em seu sistema, de modo que os múltiplos coletivos de sujeitos possam produzi-lo de acordo com a valorização da singularidade e suas possibilidades heterogêneas. É importante que o avanço tecnológico da mídia opere harmoniosamente com sua democratização, descentralizando as zonas de produção de conteúdo e de fala, contribuindo para que seu uso não seja aplicado dominantemente no sentido do lucro capitalista. Investidas nessa direção disponibilizariam vias de estímulo às práticas de exploração do eu, do outro e dos grupos em uma caminhada de ressingularização. 
Face à volumosa nuvem criada pelo conjunto das crises sociais, políticas e afetivas, pode parecer que ações no sentido da renovação da subjetividade não sejam empreendimentos capazes de transformar positiva e efetivamente a situação problemática. Ou pode parecer ainda que o crescente cultivo de mentalidades padronizadas não afete tão perigosamente a nossa evolução social. Contudo, Guattari adverte que as possibilidades para uma vigorosa guinada na direção de um mundo mais justo e menos autoritário residem justamente nessas inferências:

Novas práticas sociais, novas práticas estéticas, novas práticas de si na
relação com o outro, com o estrangeiro, com o estranho: todo um programa
que parecerá bem distante das urgências do momento! E, no entanto, é
exatamente na articulação: da subjetividade em estado nascente, do socius
em estado mutante, do meio ambiente no ponto em que pode ser reinventado,
que estará em jogo a saída das crises maiores de nossa época (GUATTARI,
2001 , p. 55).

Um fluxo capaz de movimentar-se por estas rotas poderia auxiliar na construção de modos de vida nos quais tanto os sujeitos quanto as instituições sociais que regem o cotidiano das experiências de ser e estar no mundo fossem penetrados por novos valores: os da solidariedade e do respeito ao (des)semelhante. Referimonos a transformações moleculares no estofo e na superfície de nosso meio através de injeções ressingularizantes que nos ajudem a ver as situações que nos cercam com maior autonomia.

\section{Oficinas de vídeo experimental}

Buscando por antídotos à tentativa de padronização das subjetividades por parte da mídia, o projeto das oficinas de vídeo experimental busca métodos para nadar na maré contrária dos estímulos uniformizadores da consciência emitidos pelos meios de massa. Nesse sentido, o contato com a ecosofia na pesquisa ajuda-nos a perceber que a produção de vídeo experimental apresenta brechas para inventar possíveis "antídotos para a uniformização midiática e telemática, o conformismo das modas, as manipulações da opinião pela publicidade, pelas sondagens etc." (GUATTARI, 2001, p. 16).

Bourriaud (2009, p. 118) diz que "quando se quer matar a democracia, começase arquivando a experimentação e termina-se acusando a liberdade de hidrofobia". Adaptemos a colocação do autor para a composição do conjunto imagético dos meios 
de massa, caracterizada por uma aparência asséptica estandardizada que insiste em servir-se quase sempre das mesmas etiquetas e fórmulas prontas, ignorando possíveis inovações e descobertas que produzam sentidos dissonantes em relação ao habitual.

O autor alerta para o fato de que, se quisermos fazer ruir o espetáculo criado pela grande mídia, é necessário criar novas maneiras de relação entre os sujeitos. Nessa direção, tencionamos com as oficinas, o engendramento de relações que propiciem o desnudamento de subjetividades desencadeadas através de uma consciência responsável, crítica, sensível, solidária e empática. Nesse sentido, "a finalidade última da subjetividade é a conquista incessante de uma individuação. A prática artística forma um território privilegiado dessa individuação, fornecendo modelizações potenciais para a existência humana em geral" (BOURRIAUD, 2009, p. 123).

As oficinas são pensadas como um possível caminho para experimentar novos procedimentos de reorientação dos meandros subjetivos de modo que nutram a diferença e o desvio como prolífica potencialidade inventiva. Tanto Bourriaud quanto Guattari destacam a importância de uma subjetividade trabalhada sob bases polifônicas e multipolares ao invés de uma mentalidade controlada por artimanhas uniformizadoras, que contribuem para uma sociedade cada vez mais desigual. Vertendo dessa perspectiva, Bourriaud (2009, p. 142) diz que o bojo ecosófico "consiste numa articulação ético-política entre o ambiente, o social e a subjetividade. Trata-se de reconstruir um território político perdido, visto que foi despedaçado pela violência desterritorializante do "capitalismo mundial integrado"'.

O conjunto das oficinas de vídeo ${ }^{1}$ foi pensado na perspectiva da prática audiovisual de caráter experimental no intuito de possibilitar aos participantes que pudessem explorar suas subjetividades da forma mais livre o possível, inventando e experimentando singulares maneiras de olhar e de se expressar, ângulos inusitados e novas técnicas de captura e edição audiovisual.

1 O projeto pedagógico das oficinas de vídeo experimental foi desenvolvido dentro da pesquisa de mestrado que estamos realizando no Programa de Pós-Graduação em Artes Visuais na Universidade Federal de Pelotas - UFPel. 
Tentando definir vídeo experimental, Arlindo Machado (2010) adentra o prisma cinematográfico ao contar que até a chegada da década de 1960 os filmes eram basicamente divididos entre ficções e documentários, não existindo muitos mecanismos de subversão para extrapolar esses limites. Contudo, começava a borbulhar uma tenra produção, principalmente de fora das margens do sistema comercial, que não se encaixava em delimitações simplistas. As mudanças aconteciam não só no cinema, mas também no ramo do vídeo propriamente dito através das ações de videoartistas. A partir das metamorfoses que a cena videográfica vinha sofrendo, as criações que não podiam ser inseridas nas classificações tradicionais eram denominadas como experimentais. Machado ironiza:

\footnotetext{
Mas o curioso é que o 'experimental' só pôde ser conceituado por sua exclusão, por aquilo que ele tem de atípico ou de não-padronizado, por aquilo, enfim, que não se define nem como documentário, nem como ficção, situando-se fora dos modelos, formatos e gêneros protocolares do audiovisual (MACHADO, 2010, p. 25).
}

O vídeo experimental, abrangendo criações que não se curvam a estandardizações, não necessita firmar compromisso com o circuito comercial. As obras desse nicho são salpicadas por traços e partículas que se desvencilham dos padrões mercantis. Mais do que isso, a videografia experimental abrange as produções marcadas pela importância do ato de experimentar, de arriscar, testar materiais e operações diferentes a fim de desvelar novas possibilidades, novos sentidos e sensações.

Entendendo 0 vídeo experimental como manifestação artística de desestabilização dos modelos da grande mídia audiovisual, não nos interessa a exposição exaustiva de técnicas tradicionais da produção de vídeos. Objetivamos a desestabilização de um olhar convencionado a padrões midiáticos através da experimentação de dinâmicas diferentes, ou seja, as experiências propostas na ação servem como o alimento das produções.

As oficinas estão sendo realizadas com uma turma da graduação em Artes Visuais da Universidade Federal de Pelotas. Cada encontro é dividido em três etapas. Foram escolhidos alguns assuntos, principalmente de cunho social, a serem abordados pensando em questões que poderiam ser de interesse dos participantes, 
visto que tocam na vida da população em geral e servem como dispositivos de debate e problematização da grande mídia. Nas oficinas, são realizadas conversas com o grupo para discutir esses assuntos e entender a maneira como cada um deles relaciona-se com o tema, que gira em torno, por exemplo, da situação política do país, da homofobia, da representatividade na mídia e de preconceitos que geram exclusão. Ocasionalmente, assistimos a alguns vídeos (tanto videoartes quanto fragmentos de programas da grande mídia e de filmes) que possam auxiliar na reflexão sobre o tema debatido.

Posteriormente, os participantes produzem vídeos experimentais a partir das suas visões acerca do tópico discutido. Depois que todos concluíram seus vídeos, nos reunimos novamente para assisti-los e comentar o processo de criação de cada um. Além de fazer apontamentos sobre as técnicas que foram desenvolvidas e utilizadas na produção e pós-produção audiovisual, há um diálogo sobre as diferentes significações provocadas pelos vídeos.

Em uma das oficinas, conversamos sobre a questão da empatia e de como a falta dela pode afetar nossas relações. O diálogo girou entre tópicos variados: a separação do lixo para que os profissionais da coleta possam realizar seu trabalho; a violência verbal e física contra pessoas que sofrem preconceito; decisões políticas que favorecem a exclusão de minorias. Assim, os participantes foram convidados a realizar um vídeo sobre a vivência de se colocar no lugar de outra pessoa, tentando experimentar como seria estar na pele deste outro.

Uma das participantes realizou um vídeo no qual se colocava no lugar de um trabalhador que lida com mecânica de automóveis, passando o dia inteiro em lugares quentes, com o corpo suado e sujo e tendo que fazer intenso esforço físico. Ao conversar sobre seu processo de criação, ela, que conhecia o trabalhador, relatou que finalmente entendia porque ele reclamava de fortes dores no corpo e de como sua rotina era desgastante e sofrida. Disse que passou a olhar para os trabalhadores que cruzam seu caminho diariamente de outra forma, tentando imaginar as situações pelas quais estão passando. A turma conversou bastante sobre a experiência da colega e foi possível perceber uma comoção e identificação entre eles, despertando afecções de solidariedade. 
Por mais que exista um plano delineado para cada uma das oficinas, tanto a sua execução quanto a elaboração da pesquisa em torno da sua realização são inspiradas pelo método da cartografia (BARROS e KASTRUP, 2015; ROMAGNOLI, 2009). Dessa forma, durante o percurso algumas modificações são realizadas em função de sugestões feitas pelos participantes e outros acontecimentos que surgem no caminho. Ao encontrarmo-nos com a turma participante, não portamos um objetivo fixo a ser alcançado. Pelo contrário, levamos uma proposta flexível que se constrói na cumplicidade do grupo, na relação de agenciamento entre indivíduos heterogêneos, afinal, "a pesquisa cartográfica consiste no acompanhamento de processos, e não na representação de objetos" (BARROS e KASTRUP, 2015, p. 53).

Um diário de bordo vem sendo mantido para que seja possível a eficiência do mapeamento da experiência, visto que nele são feitos, como recomendam as autoras Barros e Kastrup (2015, p. 70): "relatos regulares, após as visitas e as atividades, que reúnem tanto informações objetivas quanto impressões que emergem no encontro com o campo". Os processos, ideias e cisões empreendidas ao longo da execução das oficinas vão integrando a produção de dados a respeito dos resultados do projeto.

\section{Breves considerações em fluxo}

Analisando a grande mídia audiovisual que permeia a cultura visual pósmoderna é possível constatar que os estímulos à uniformização dos corpos e das mentalidades constituem uma ameaça à democracia e aos modos de vida mais igualitários. Fazemos tal afirmação tendo em vista que o desenvolvimento de nossas subjetividades é afetado pelas mensagens, tanto verbais quanto sonoras e visuais, provindas da mídia. Essas mensagens são elaboradas em um formato que tenciona impulsionar o consumo através da laminagem das singularidades dos indivíduos buscando criar desejos a serem satisfeitos com produtos serializados. Assim, percebemos que um dos objetivos da mídia é a formatação mascarada de seres humanos que sejam capazes de se conformar com modos de vida muitas vezes precários e com pouca participação em decisões importantes que definem o curso de nossas existências. 
As oficinas têm se evidenciado como uma potente ferramenta para pensar sobre e problematizar essas estruturas de manipulação mental presentes na esfera midiática audiovisual. As dinâmicas realizadas aproximaram os participantes, que construíram relações de empatia uns com os outros por intermédio da criação de vídeos experimentais. As produções criadas pelos integrantes do grupo, além de serem assistidas coletivamente pela turma, seguidas de proveitosas conversas sobre a pauta de cada vídeo, serão exibidas em uma mostra organizada na universidade aberta ao público. A mostra possibilitará que mais pessoas possam conhecer os vídeos, podendo então inserir-se nos debates a respeito dos assuntos que serviram como gatilhos para o processo criativo dos participantes da oficina.

Acreditamos na necessidade de iniciativas dessa natureza no contexto do ensino das Artes Visuais, que possibilitem aos discentes um processo de descoberta e exploração livre de suas subjetividades no intuito de tentar desconstruir os mecanismos de produção de subjetividade midiáticos. O momento político pelo qual nosso país passa, permeado por retrocessos e destruição de alguns direitos humanos, reforça a importância dessas ações, já que alguns veículos de mídia são também responsáveis por mascarar as ideologias de governo para vendê-las à população de maneira atraente. Nesse sentido, a criação artística é tomada como um instrumento de questionamento da realidade e de resistência ao poder dominante.

\section{Referências}

ADORNO, Theodor. Indústria cultural e sociedade. 10. ed. São Paulo: Paz e Terra, 2016.

BOURRIAUD, Nicolas. Estética Relacional. São Paulo: Martins, 2009.

BARROS, Laura Pozzana de; KASTRUP, Virgínia. Cartografar é acompanhar processos. In: PASSOS, Eduardo; KASTRUP, Virgínia; ESCÓSSIA, Liliana da (Org.). Pistas do método da cartografia: pesquisaintervenção e produção de subjetividade. Porto Alegre: Sulina, 2015. p. 52-75.

CHAUI, Marilena. Simulacro e poder: uma análise da mídia. São Paulo: Editora Fundação Perseu Abramo, 2006.

GUATTARI, Félix. As três ecologias. 11. ed. Campinas: Papirus, 2001.

MACHADO, Arlindo. Pioneiros do vídeo e do cinema experimental na américa latina. Significação: Revista de Cultura Audiovisual, São Paulo, v. 37, n. 33, p. 21-40, jun./set. 2010.

MIRZOEFF, Nicholas. Una introducción a la cultura visual. Barcelona: Paidós Arte y Educación, 2003.

ROMAGNOLI, Roberta. A cartografia e a relação pesquisa e vida. Psicologia \& Sociedade, Florianópolis, v. 21, n. 2, p. 166-173, ago. 2009. 


\section{Jéssica Thaís Demarchi}

Mestranda do Programa de Pós-Graduação em Artes Visuais da Universidade Federal de Pelotas (PPGAV/UFPEL). Integrante do grupo de pesquisa "Núcleo Transdisciplinar de Estudos Estéticos/ NUTREE" liderado pela Dra. Mirela Ribeiro Meira e do grupo "Arte, Ecologia e Saúde" liderado pelo Dr. Cláudio Tarouco de Azevedo. Graduou-se em Artes Visuais - Licenciatura pela Universidade Federal do Rio Grande - FURG.

E-mail: jessicathaisdemarchi@gmail.com

Currículo: http://lattes.cnpq.br/1636624251164241

\section{Cláudio Tarouco de Azevedo}

Pós-doutor em Artes Visuais (2016), doutor (2013) e mestre (2010) em Educação Ambiental e graduado em Artes Visuais Licenciatura. Professor do Curso de Artes Visuais e do Mestrado em Artes Visuais da Universidade Federal de Pelotas - UFPel. Participa do Núcleo Transdisciplinar de Estudos Estéticos NUTREE e lidera o Grupo de Pesquisa Arte, Ecologia e Saúde - GPAES.

E-mail: claudiohifi@yahoo.com.br

Currículo: http://lattes.cnpq.br/8041917371066975

Recebido em 15 de julho de 2017 Aceito em 21 de novembro de 2017 